\title{
Total energy expenditure of 10- to 12- year-old Japanese children measured using the doubly labeled water method
}

Keisuke Komura ${ }^{1,2}$, Satoshi Nakae ${ }^{3}$, Kazufumi Hirakawa $^{4}$, Naoyuki Ebine ${ }^{5}$, Kazuhiro Suzuki ${ }^{6}$, Haruo Ozawa ${ }^{7}$ Yosuke Yamada ${ }^{3}$, Misaka Kimura ${ }^{4}$ and Kojiro Ishii $^{5^{*}}$

\begin{abstract}
Background: To establish Japanese children's estimated energy requirements, total energy expenditure (TEE) data measured using the doubly labeled water (DLW) method is needed. This study aimed to 1) obtain basic TEE data from Japanese children measured using DLW (TEE $\left.E_{D L W}\right)$, 2) compare TEE $E_{D L W}$ with TEE estimated by various estimation formulas to calculate their accuracy, and 3) develop a new equation to estimate TEE using body composition and pedometers.

Methods: TEE was measured using DLW in 56 10- to 12-year-old Japanese children (33 boys, 23 girls). Physical activity level (PAL) was calculated by dividing TEE physical activity, participants wore pedometers during the 7-d DLW period. Total body water was calculated from ${ }^{2} \mathrm{H}$ and ${ }^{18} \mathrm{O}$; fat-free mass (FFM) and fat mass (FM) were then determined.

Results: In boys and girls of normal weight, TEE ELw was $2067 \pm 230 \mathrm{kcal} / \mathrm{d}$ and $1830 \pm 262 \mathrm{kcal} / \mathrm{d}$, respectively. Average PAL was $1.58 \pm 0.17$. FFM was strongly related to TEE $(r=0.702, p<0.01)$. After adjusting for FFM and FM, step count was significantly associated with TEE $(r=0.707, p<0.01)$. The TEE estimation formula used in the Dietary Reference Intakes (DRI) for the United States and Canada estimated TEEDLw with high accuracy (bias: 2.0\%) in both sexes. We developed new equations for TEE consisting of FFM and step count, which accounted for $68 \%$ and $65 \%$ of TEE variance in boys and girls, respectively: boys, $47.1 \times$ FFM $(\mathrm{kg})+0.0568 \times$ step count (steps/d) -122 , and girls, $55.5 \times$ FFM $(\mathrm{kg})+0.0315 \times$ step count (steps $/ \mathrm{d})-117$.

Conclusions: The TEE in 10- to 12-year-old Japanese children measured using DLW was approximately 7\% lower for boys and 12\% lower for girls compared to the current Japanese DRI. If PAL can be accurately determined, the equation in the DRI for the United States and Canada may be applicable to Japanese children. In addition, TEE could be predicted using FFM and step count.
\end{abstract}

Keywords: Total energy expenditure, Doubly labeled water, Fat-free mass, Fat mass, Deuterium, Pre-adolescent children, Estimated energy requirement, Physical activity level

\footnotetext{
* Correspondence: kishii@mail.doshisha.ac.jp

${ }^{5}$ Faculty of Health and Sports Science, Doshisha University, Kyoto, Japan

Full list of author information is available at the end of the article
} 


\section{Background}

Estimated energy requirements (EER) as indicated in Dietary Reference Intakes for Japanese (Japan-DRI) [1] are defined as "habitual energy intake in a day which is predicted to have the highest probability that energy balance (energy intake - energy expenditure, in adults) becomes zero in a group [2]." EER can be estimated from dietary assessment by assuming that the energy intake and energy requirement are equal when weight does not fluctuate substantially over a short time, but this method underestimates EER [3]. Therefore, energy intake is assumed to equal total energy expenditure (TEE), and generally EER is estimated from TEE [4]. In children, when estimating EER from TEE, energy deposition for growth must be added (EER $=\mathrm{TEE}+$ energy deposition) [5].

Doubly labeled water (DLW) is the most accurate TEE estimation method under free-living conditions [6, 7], but it is expensive and requires specialized analysis equipment [8], making large-scale data collection difficult. The Japan-DRI refers to only 2 reports of DLW data from Japanese children [9, 10]. Consequently, the EER of Japanese children is determined based on other nationalities. To establish the EER of Japanese children, data using the DLW method must be collected to serve as a gold-standard population reference.

In the current Japan-DRI, children's TEE is estimated by multiplying basal metabolic rate (BMR), determined by multiplying the sex- and age-specific BMR standard value per unit body weight by body weight, by the physical activity coefficients (PA) determined by the physical activity level (PAL) [4]. In obese adults, estimation using the BMR standard was reported to overestimate BMR [11]. However, the accuracy of the BMR standard to estimate TEE in children remains unknown. Moreover, the possible appropriateness of other TEE estimation formulae [5, 12] for children in Japan has not been established [4].

The largest component of TEE is typically BMR, which is determined by body size and composition, particularly fat-free mass (FFM) [13], and the interindividual variability of TEE adjusted using FFM (or BMR) indicates inter-individual differences in physical activity energy expenditure. Therefore, by measuring body composition and physical activity, TEE might be predictable to some extent without the DLW method.

The current study aimed to 1) obtain baseline TEE data from Japanese children with the DLW method, 2) examine the accuracy of previously proposed TEE estimation equations, and 3) develop a new TEE estimation equation for 10- to 12-year-old children in Japan using body composition and pedometer data.

\section{Methods}

\section{Participants}

Physical activity levels significantly differ between rural and urban Japanese children [14]. Therefore, we recruited 62 healthy elementary school attendees (5th to 6th grade; age 10 to 12 years) in a rural area (Chiba prefecture) and an urban area (Hyogo prefecture). Fifth graders $(n=38)$ were measured in November 2006 (rural area, $n=36$ ) and November to December 2007 (urban area, $n=2$ ), and 6th graders (urban area, $n=24$ ) were measured in February 2009, all during school days in a typical week. The inclusion criteria were healthy subjects without illness, with informed consent to participate in the study obtained from children and their parents. The experimental protocol compliant with the Code of Ethics of the World Medical Association (Declaration of Helsinki) and conducted with approval of the ethics committee of the Graduate School of Education, Hokkaido University (H18-04).

To assess their physical activity, participants wore pedometers (Omron, Kyoto, Japan) [15, 16] on their waist during the 7-d DLW period except when taking a bath or shower, swimming, and sleeping. We excluded subjects who spilled DLW during administration $(n=1)$, with stable isotope concentrations higher at $24 \mathrm{~h}$ than at $4 \mathrm{~h}$ after DLW administration $(n=3)$, who were absent on urine sample collection days $(n=2)$, or who wore the pedometer less than 3 days for $\geq 10 \mathrm{~h}$ per day during the 7-d DLW measurement period. The final dataset was obtained from 56 children (33 boys and 23 girls) for DLW and body composition data and from 52 children (31 boys and 21 girls) for step counts per day.

\section{Total energy expenditure measurements using DLW}

Total energy expenditure was measured over $7 \mathrm{~d}$ as described previously $[17,18]$. Height and body weight (BW) were measured in underwear on the day of DLW administration. Subjects were administered $\sim 0.18 \mathrm{~g} / \mathrm{kg}$ BW ${ }^{2} \mathrm{H}_{2} \mathrm{O}$ (99.8 atom\%; Taiyo Nippon Sanso, Tokyo, Japan) and $\sim 3.6 \mathrm{~g} / \mathrm{kg} \mathrm{BW} \mathrm{H}_{2}^{18} \mathrm{O}$ (10.0 atom\%; Taiyo Nippon Sanso). To ensure that all DLW was consumed, after the subject drank the DLW, we rinsed the container with a total of $50 \mathrm{~mL}$ commercial mineral water, which the subject also drank, and then repeated this procedure. Urine samples were collected before and $4 \mathrm{~h}, 1 \mathrm{~d}, 4 \mathrm{~d}$, and $7 \mathrm{~d}$ after DLW administration. All participants included in the final dataset $(n=56)$ provided all five urine samples under a researcher's or teacher's supervision.

The urine samples were analyzed in duplicate or triplicate using stable isotope ratio mass spectrometry (Hydra 20-20, SerCon Ltd., Crewe, UK) with gas $\left(\mathrm{H}_{2}\right.$ or $\mathrm{CO}_{2}$ ) equilibration methods, a platinum catalyst for $\mathrm{H}_{2}$, and commercially available stable isotope standards (Iso- 
Analytical, Crewe, UK). The average standard deviations (SD) were $0.25 \mathrm{ppm}$ for ${ }^{2} \mathrm{H}$ and $0.40 \mathrm{ppm}$ for ${ }^{18} \mathrm{O}$. The ${ }^{2} \mathrm{H}$ and ${ }^{18} \mathrm{O}$ dilution spaces ( $\mathrm{Nd}$ and $\mathrm{No}$ ) were determined using the plateau method. The mean $\pm \mathrm{SD} \mathrm{Nd} / \mathrm{No}$ in the present study was $1.031 \pm 0.008$ (range, 1.0041.059), which is acceptable based on previous studies $[19,20]$. Thus, total body water (TBW) (g) was calculated as the average of the value obtained by dividing the dilution space of ${ }^{2} \mathrm{H}$ by 1.041 and the value obtained by dividing the dilution space of ${ }^{18} \mathrm{O}$ by 1.007 . TBW (mol) was obtained as TBW (g)/18.02, and carbon dioxide production rate $\left(\mathrm{rCO}_{2}\right)\left(\mathrm{mol} \mathrm{d}^{-1}\right)$ was calculated as $0.4554 \times \mathrm{TBW}(\mathrm{mol}) \times\left(1.007 \times{ }^{18} \mathrm{O}\right.$ elimination rate [ko] $-1.041 \times{ }^{2} \mathrm{H}$ elimination rate $\left.[\mathrm{kd}]\right)$, assuming that isotope fractionation applies only to breath water using eq. A6 by Schoeller et al. [21] with the revised dilution space constant provided by Racette et al. [19]. The average determinant coefficients $\left(\mathrm{R}^{2}\right)$ of ko and kd were 0.997 and 0.995 , respectively. The $\mathrm{rCO}_{2}\left(\mathrm{~L} \mathrm{~d}^{-1}\right)$ was obtained as $22.4 \times \mathrm{rCO}_{2}\left(\mathrm{~mol} \mathrm{~d}^{-1}\right)$. We assumed that the respiratory quotient (RQ) was 0.85 [22], and TEE was calculated using the modified Weir's equation [23] as follows: TEE $(\mathrm{kcal} / \mathrm{d})=1.1 \mathrm{rCO}_{2}+3.9 \mathrm{rCO}_{2} / \mathrm{RQ}$. The detailed quality checklist is described in International Atomic Energy Agency (IAEA) documents [24]. FFM was calculated using TBW with the age-dependent hydration factor of children [25]. Fat mass (FM) and percent fat (\% fat) were calculated using FFM and BW. PAL was obtained by dividing TEE measured with the DLW method (TEE $E_{\text {DLW }}$ ) by resting energy expenditure (REE) from an estimation formula [26] obtained from Japanese children: for boys, $14.4 \times \mathrm{BW}(\mathrm{kg})+5.09 \times$ height $(\mathrm{cm})-34.0 \times$ age $(\mathrm{y})+403$, and for girls, $7.64 \times \mathrm{BW}$ $(\mathrm{kg})+4.22 \times$ height $(\mathrm{cm})-22.5 \times$ age $(\mathrm{y})+526$. We assumed an age of 10 years for 5th graders and 11 years for 6th graders.

\section{Predictive equations of total energy expenditure}

The applicability of the three predictive estimations of TEE is shown in Table 1.

\section{Statistical analysis}

Results are presented as means $\pm \mathrm{SD}$. Analysis of covariance (ANCOVA) was used to analyze sex differences adjusting for measurement timing, because the measurement sites (urban vs. rural) and seasons (Oct.-Nov. vs Feb.) were potential confounders. To examine factors related to TEE, we used partial correlation analysis, also adjusting for measurement timing. To standardize FFM, we treated FFM as a covariate, because the intercept of the linear regression of FFM $(x)$ against TEE (y) significantly differed from zero [27]. To analyze the differences and relationships between $\mathrm{TEE}_{\mathrm{DLW}}$ and each estimated TEE, repeated-measures analysis of covariance with Bonferroni correction and partial correlation coefficient, adjusting for measurement timing, was used. The accuracy of estimated TEE was evaluated using Bland-Altman plots and root mean squared error (RMSE) as follows: $R M S E=\sqrt{\Sigma(\text { predicted TEE-measured TEE })^{2} / n}$. The relationship between BMI and bias (predicted TEE measured TEE) was analyzed by partial correlation, adjusting for measurement timing. Multiple linear regression analyses for predicting TEE, FFM, and step counts were entered into the regression equation simultaneously. The threshold for statistical significance was $p<0.05$. SPSS Statistics 23 software (IBM Inc., Japan, Tokyo) was used for statistical analysis.

\section{Results}

Table 2 shows the physical characteristics, body composition, TEE, REE, PAL, and daily step counts. Subjects' average height and body weight ranged from $100 \%$ to $106 \%$ of the corresponding reference values [4] of the Japan-DRI. Compared to the corresponding FFMs measured using bioelectrical impedance in a previous study [26], the present FFMs were slightly higher (112\% for boys, $106 \%$ for girls). Step counts were similar to those of previously reported Japanese subjects (aged $8.9 \pm 1.8$, for boys: $12,152 \pm 2804$ steps/d, for girls: $10,408 \pm 1808$ steps/d)

Table 1 Predictive equations of total energy expenditure (TEE)

\begin{tabular}{|c|c|}
\hline & Predictive equations \\
\hline TEE J-DRI $(k c a l / d)[4]$ & BMR standard ${ }^{\mathrm{a}}(\mathrm{kcal} / \mathrm{kg} / \mathrm{d}) \times$ body weight $(\mathrm{kg}) \times \mathrm{PA}_{\mathrm{J}-\mathrm{DRI}}^{\mathrm{a}}$ \\
\hline \multirow[t]{2}{*}{ TEE } & For boys aged 9-18 y: 88.5-61.9 $\times$ age $(\mathrm{y})+\mathrm{PA}_{1 \mathrm{OM}}^{\mathrm{d}} \times[26.7 \times$ body weight $(\mathrm{kg})+903 \times$ height $(\mathrm{m})]$ \\
\hline & For girls aged 9-18 y: 135.3-30.8 $\times$ age $^{c}(\mathrm{y})+\mathrm{PA}_{\mathrm{IOM}}^{\mathrm{d}} \times[10.0 \times$ body weight $(\mathrm{kg})+934 \times$ height $(\mathrm{m})]$ \\
\hline \multirow[t]{2}{*}{$\mathrm{TEE}_{\mathrm{FAO}}(\mathrm{kcal} / \mathrm{d})[12]$} & For boys aged $1-18$ y: $310.2+63.3 \times$ body weight $(\mathrm{kg})-0.263 \times$ body weight $(\mathrm{kg})^{2}$ \\
\hline & For girls aged $1-18$ y: $263.4+65.3 \times$ body weight $(\mathrm{kg})-0.454 \times$ body weight $(\mathrm{kg})^{2}$ \\
\hline
\end{tabular}

${ }^{a}$ BMR standard is $37.4 \mathrm{kcal} / \mathrm{kg} / \mathrm{d}$ for boys and $34.8 \mathrm{kcal} / \mathrm{kg} / \mathrm{d}$ for girls [4]

${ }^{\mathrm{b}}$ Physical activity coefficients (PA) determined by PAL in Japan-DRI $\left(\mathrm{PA}_{\text {J-DRI }}\right.$ ) [4] are as follows: if $\mathrm{PAL}<1.55, \mathrm{PA}=1.45$ (level I); if $1.55 \leq \mathrm{PAL}<1.75, \mathrm{PA}=1.65$ (level II); and if $1.75 \leq \mathrm{PAL}$, and PA $=1.85$ (level III) for both boys and girls

'We assumed an age of 10 years for 5 th graders and 11 years for 6th graders

${ }^{\mathrm{d}} \mathrm{PA}$ used in the DRI for the United States and Canada developed by the Institute of Medicine (IOM) (PA $\left.\mathrm{IOM}\right)[5]$ are as follows: boys, sedentary (1.0 $\leq \mathrm{PAL}<1.4$, $\mathrm{PA}=1.00)$, low activity $(1.4 \leq \mathrm{PAL}<1.6, \mathrm{PA}=1.13)$, active $(1.6 \leq \mathrm{PAL}<1.9, \mathrm{PA}=1.26)$, and very active $(1.9 \leq \mathrm{PAL}<2.5, \mathrm{PA}=1.42)$; girls,: sedentary $(\mathrm{PA}=1.00)$, low activity $(P A=1.16)$, active $(P A=1.31)$, and very active $(P A=1.56)$ 
Table 2 Characteristics of the subjects

\begin{tabular}{|c|c|c|c|c|c|}
\hline & \multicolumn{2}{|c|}{ Boys } & \multicolumn{2}{|c|}{ Girls } & \multirow[b]{2}{*}{$p^{i}$} \\
\hline & $n$ & Mean \pm SD & $n$ & Mean \pm SD & \\
\hline Height (cm) & 33 & $142.6 \pm 6.9$ & 23 & $145.5 \pm 6.6$ & 0.265 \\
\hline Body weight (kg) & 33 & $37.9 \pm 6.7$ & 23 & $36.7 \pm 6.3$ & 0.458 \\
\hline $\mathrm{BMI}^{\mathrm{a}}\left(\mathrm{kg} / \mathrm{m}^{2}\right)$ & 33 & $18.6 \pm 2.8$ & 23 & $17.2 \pm 1.9$ & 0.092 \\
\hline Overweight [n (\%)] & & $6(18 \%)$ & & $1(4 \%)$ & \\
\hline Obesity [n (\%)] & & $1(3 \%)$ & & $0(0 \%)$ & \\
\hline $\mathrm{FFM}^{\mathrm{b}}(\mathrm{kg})$ & 33 & $31.9 \pm 4.3$ & 23 & $29.6 \pm 4.0$ & 0.110 \\
\hline $\mathrm{FM}^{\mathrm{c}}(\mathrm{kg})$ & 33 & $6.0 \pm 3.7$ & 23 & $7.1 \pm 4.5$ & 0.609 \\
\hline$\%$ fat (\%) & 33 & $15.1 \pm 7.2$ & 23 & $18.6 \pm 9.4$ & 0.387 \\
\hline $\operatorname{TEE}_{\mathrm{DLW}^{-1}}{ }^{\mathrm{d}}(\mathrm{kcal} / \mathrm{d})$ & 33 & $2107 \pm 273$ & 23 & $1847 \pm 269$ & 0.002 \\
\hline $\operatorname{REE}^{\mathrm{e}}(\mathrm{kcal} / \mathrm{d})$ & 33 & $1321 \pm 113$ & 23 & $1185 \pm 69$ & 0.000 \\
\hline $\operatorname{PAL}^{f}$ & 33 & $1.60 \pm 0.16$ & 23 & $1.56 \pm 0.19$ & 0.626 \\
\hline Step count (steps/d) ${ }^{9}$ & 31 & $12,823 \pm 2945$ & 21 & $10,526 \pm 2493$ & 0.009 \\
\hline TEE $_{D L w}-2^{h}$ (kcal/d) & 26 & $2067 \pm 230$ & 22 & $1830 \pm 262$ & 0.004 \\
\hline \multicolumn{6}{|c|}{ 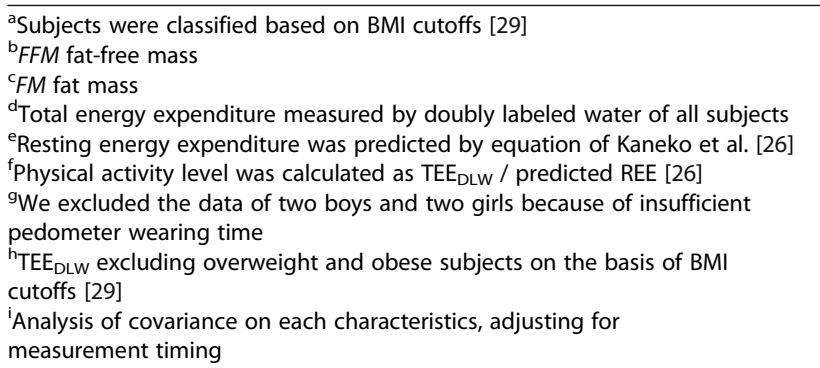 } \\
\hline
\end{tabular}

[28]. Six boys and one girl were overweight, and one boy was obese based on BMI cutoffs [29]. TEE ${ }_{\text {DLW, }}$ predicted REE, and step counts were significantly higher in boys than girls; however, there was no significant sex difference for PAL (overall average PAL $[n=56], 1.58 \pm$ 0.17). Excluding overweight and obese subjects,
$\mathrm{TEE}_{\mathrm{DLW}}$ was $2067 \pm 230 \mathrm{kcal} / \mathrm{d}$ for boys and $1830 \pm$ $262 \mathrm{kcal} / \mathrm{d}$ for girls.

Table 3 shows the partial correlations between TEE and body size, body composition, and step count. After adjusting for measurement timing, FFM showed the highest correlation coefficient in both boys and girls. After adding FFM as a covariate, only step count was significantly associated with TEE for both sexes. This result did not change after adjustment with FM.

Table 4 shows the accuracy and association of each estimated TEE compared to $\mathrm{TEE}_{\mathrm{DLW}}$. $\mathrm{TEE}_{\text {J-DRI }}$ and $\mathrm{TEE}_{\mathrm{FAO}}$ significantly differed from $\mathrm{TEE}_{\mathrm{DLW}} \cdot \mathrm{TEE}_{\mathrm{IOM}}$ demonstrated the smallest bias and RMSE (both sexes: bias, 2.0\%; accurate estimation rate $\geq 90 \%$ ). Partial correlation analysis indicated significant relationships between $\mathrm{TEE}_{\mathrm{DLW}}$ and all estimated TEEs for both boys and girls.

Fig. 1 shows Bland-Altman plots using three predictive equations and the relationships between BMI and bias (predicted TEE - measured TEE). The IOM equation had the smallest difference in the mean $(42 \mathrm{kcal} / \mathrm{d})$ and limits of agreements $(-147$ to $230 \mathrm{kcal} / \mathrm{d})$. The range of limits of agreement was similar for the FAO equation ( -288 to $691 \mathrm{kcal} / \mathrm{d})$ and Japan-DRI (-358 to $674 \mathrm{kcal} / \mathrm{d})$. Bias was strongly related to $\mathrm{BMI}$ in both sexes for $\mathrm{TEE}_{\mathrm{J} \text {-DRI}}$, whereas this relationship was weakly significant in boys and not significant in girls for both $\mathrm{TEE}_{\mathrm{IOM}}$ and $\mathrm{TEE}_{\mathrm{FAO}}$. $\mathrm{TEE}_{\mathrm{IOM}}$ estimated TEE within $\pm 10 \%$ bias even for overweight or obese individuals.

To predict TEE, FFM and step count were entered into the multiple regression analysis simultaneously (Table 5 ). For boys, the TEE $(\mathrm{kcal} / \mathrm{d})$ predictive equation was $47.1 \times$ FFM $(\mathrm{kg})+0.0568 \times$ step count $($ steps $/ \mathrm{d})-122$, and for girls, $55.5 \times$ FFM $(\mathrm{kg})+0.0315 \times$ step count

Table 3 Partial correlation between TEE (kcal/d) and height, body weight (BW), body composition and step count

\begin{tabular}{|c|c|c|c|c|c|c|c|c|}
\hline Covariates & Subject & $n$ & Height & BW & $\mathrm{FFM}^{\mathrm{a}}$ & $\mathrm{FM}^{\mathrm{b}}$ & $\%$ fat & Steps \\
\hline \multirow[t]{3}{*}{ none } & Boys and girls & 52 & $0.365^{* *}$ & $0.521^{* *}$ & $0.702^{* *}$ & 0.088 & -0.091 & $0.430^{* *}$ \\
\hline & Boys & 31 & $0.513^{* *}$ & $0.609^{* *}$ & $0.618^{* *}$ & $0.379^{*}$ & 0.276 & $0.447^{*}$ \\
\hline & Girls & 21 & $0.517^{*}$ & $0.425^{*}$ & $0.767^{* *}$ & -0.089 & -0.314 & 0.129 \\
\hline \multirow[t]{3}{*}{$\mathrm{MT}^{\mathrm{c}}$} & Boys and girls & 52 & $0.385^{* *}$ & $0.535^{* * *}$ & $0.673^{* * *}$ & 0.178 & 0.006 & $0.388^{* *}$ \\
\hline & Boys & 31 & 0.356 & $0.619^{* * *}$ & $0.637^{* * *}$ & $0.381^{*}$ & 0.245 & $0.375^{*}$ \\
\hline & Girls & 21 & $0.735^{* * *}$ & $0.675^{* *}$ & $0.771^{* * *}$ & 0.311 & 0.038 & 0.075 \\
\hline \multirow[t]{3}{*}{$\mathrm{MT}^{c}$ and FFM } & Boys and girls & 52 & -0.155 & -0.065 & - & -0.065 & -0.054 & $0.695^{* * *}$ \\
\hline & Boys & 31 & -0.128 & 0.185 & - & 0.185 & 0.184 & $0.708^{* * *}$ \\
\hline & Girls & 21 & 0.107 & 0.049 & - & 0.049 & 0.054 & $0.546^{*}$ \\
\hline \multirow[t]{3}{*}{$\mathrm{MT}^{c}, \mathrm{FFM}$ and $\mathrm{FM}$} & Boys and girls & 52 & -0.153 & - & - & - & 0.040 & $0.707^{* * *}$ \\
\hline & Boys & 31 & -0.123 & - & - & - & 0.012 & $0.696^{* * *}$ \\
\hline & Girls & 21 & 0.097 & - & - & - & 0.023 & $0.548^{*}$ \\
\hline
\end{tabular}

\footnotetext{
Fat-free mass derived from total body water

${ }^{b}$ Fat mass calculated by subtracting FFM from body weight

${ }^{c}$ Measurement timing

${ }^{* *} p<0.05,{ }^{* *} p<0.01,{ }^{* * *} p<0.001$
} 
Table 4 Differences and correlations between the predicted and measured total energy expenditure (TEE)

\begin{tabular}{|c|c|c|c|c|c|c|c|}
\hline & $\begin{array}{l}\text { TEE Mean (SD) } \\
\mathrm{kcal} / \mathrm{d}\end{array}$ & $\begin{array}{l}\text { Bias Mean } \\
{[95 \% \mathrm{Cl}] \%}\end{array}$ & $\begin{array}{l}\mathrm{RMSE}^{\mathrm{e}} \\
\mathrm{kcal} / \mathrm{d}\end{array}$ & Accurate estimation ${ }^{f} \%$ & Under estimation ${ }^{9} \%$ & Over estimation ${ }^{\mathrm{h}} \%$ & $\begin{array}{l}\text { Correlation } \\
\text { coefficient }\end{array}$ \\
\hline \multicolumn{8}{|l|}{ Boys $(n=33)$} \\
\hline TEE & 2107 (273) & & & & & & \\
\hline \multicolumn{8}{|c|}{ TEE predicted } \\
\hline$T E_{J-D R I}^{b}$ & $2264(470)^{*}$ & $6.8[2.6,11.1]$ & 302.8 & 63.6 & 3.0 & 33.3 & $0.885^{\dagger}$ \\
\hline TEE IOM & $2153(321)$ & $2.0[0.3,3.7]$ & 110.2 & 93.9 & 0.0 & 6.1 & $0.944^{\dagger}$ \\
\hline $\mathrm{TEE}_{\mathrm{FAO}}^{\mathrm{d}}$ & $2320(279)^{*}$ & $10.9[6.7,15.0]$ & 319.9 & 57.6 & 0.0 & 42.4 & $0.635^{\dagger}$ \\
\hline \multicolumn{8}{|l|}{ Girls $(n=23)$} \\
\hline$T E E_{D L W}^{a}$ & $1847(269)$ & & & & & & \\
\hline \multicolumn{8}{|c|}{ TEE predicted } \\
\hline TEE $E_{\text {-DRI }}^{\mathrm{b}}$ & $2007(401)^{*}$ & $8.6[2.9,14.2]$ & 297.8 & 69.6 & 4.3 & 26.1 & $0.854^{\dagger}$ \\
\hline $\mathrm{TEE}_{\mathrm{IOM}}^{\mathrm{C}}$ & $1882(271)$ & $2.0[0.1,3.9]$ & 90.0 & 100.0 & 0.0 & 0.0 & $0.941^{\dagger}$ \\
\hline$T_{E E}^{d} E_{F A O}$ & $2031(183)^{*}$ & $11.5[5.7,17.4]$ & 308.2 & 34.8 & 4.3 & 60.9 & $0.654^{\dagger}$ \\
\hline
\end{tabular}

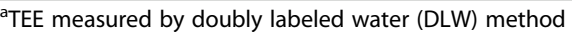

${ }^{\mathrm{b}}$ TEE estimated by equation of Dietary Reference Intakes (DRI) for Japanese [4], basal metabolic rate (BMR) standard $(\mathrm{kcal} / \mathrm{kg} / \mathrm{d}) \times$ body weight $(\mathrm{kg}) \times \mathrm{PA} \mathrm{J}_{\mathrm{J}} \mathrm{DRI}$ (physical activity coefficient)

'TEE estimated by equation of Institute of Medicine (IOM) [5]

${ }^{d}$ TEE estimated by equation of FAO (Food and Agriculture Organization of the United Nations) [12]

${ }^{\mathrm{e}}$ Root mean squared error

${ }^{f}$ Percentage of the subjects predicted by equation within $\pm 10 \%$ of measured TEE

${ }^{9}$ Percentage of the subjects predicted by equation $<90 \%$ of measured TEE

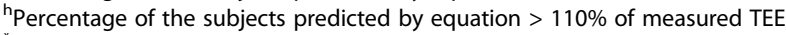

"Significantly different from TEE $\mathrm{DLW}_{1} p<0.05$ (repeated measures analysis of covariance with Bonferroni correction, adjusting for measurement timing)

${ }^{+}$Signigicantly correlate with $\mathrm{TEE}_{\mathrm{DL},}, p<0.05$ (Partial correlation coefficient, adjusting for measurement timing)

(steps/d) - 117, which accounted for $68 \%$ and $65 \%$ of the TEE variance, respectively. Standard errors were $277 \mathrm{kcal} /$ $\mathrm{d}$ for boys and $333 \mathrm{kcal} / \mathrm{d}$ for girls.

\section{Discussion}

We found that $\mathrm{TEE}_{\mathrm{DLW}}$ of 10- to 12-year-old Japanese children was lower than current Japan-DRI criteria [4]. Furthermore, the IOM TEE equation [5] was applicable to Japanese children, and TEE could be predicted to some extent using FFM and step count.

The TEE indicated by the Japan-DRI is $2210 \mathrm{kcal} / \mathrm{d}$ for boys and $2070 \mathrm{kcal} / \mathrm{d}$ for girls [4]. Compared to the $\mathrm{TEE}_{\mathrm{DLW}}$ of non-overweight or -obese children in the present study (boys: $2067 \pm 230 \mathrm{kcal} / \mathrm{d}$, girls: $1830 \pm$ $262 \mathrm{kcal} / \mathrm{d}$ ), TEE of the Japan-DRI was approximately $7 \%$ higher for boys and $12 \%$ higher for girls. Moreover, $\mathrm{TEE}_{\mathrm{J}-}$ DRI overestimated $\mathrm{TEE}_{\mathrm{DLW}}$ (Table 4). The only study of TEE in Japanese children aged 10 to 12 years cited by the Japan-DRI reported that TEE at an average age of $11.2 \pm$ 1.0 years (boys: $n=5$, girls: $n=7$ ) was $1968 \pm 299 \mathrm{kcal} / \mathrm{d}$ [9], which is lower than the TEE of the Japan-DRI, also suggesting that the EER of 10- to 12-year-old children in the current Japan-DRI may overestimate actual energy requirements.

FFM was reported to predict about $60 \%$ of TEE in elementary school children [27, 30]. While we also found a significant relationship between FFM and TEE, FFM explained $40-50 \%$ of inter-individual TEE variability in the present study, due to differences in participants' range of FFM. FM also relates to TEE, because greater body size affects both REE and activity-related expenditure (AEE) through cost of weight-bearing activities [31]. These relationships are supported by the finding that children's FFM was related to TEE, REE, and AEE, regardless of ethnicity [27]. Hence, the current and previous studies indicate that FFM is the major determinant of TEE in elementary school children.

We used step count as a physical activity index, as in previous studies [32, 33]. Step count was significantly related with TEE in both sexes after adjusting for FFM and FFM + FM, suggesting step count can explain interindividual differences other than body size. Indeed, predictive equations consisting of FFM $(\mathrm{kcal} / \mathrm{d})$ and daily step count could account for $65 \%$ or more of TEE variance (Table 5). Previous studies reported that nonlocomotive activity significantly impacted PAL [32], and girls' step counts were not significantly related to PAL [33]. Thus, the predictive equation might be improved by adding measurements of non-locomotive activities, such as active standing or organized sports. Since approximately $90 \%$ of non-locomotive activities are light-intensity physical activity and strongly related with sedentary time [34], measurement of sedentary time may also be useful.

If PA can be accurately determined, the IOM equation estimates TEE with good accuracy and limited influence 
a

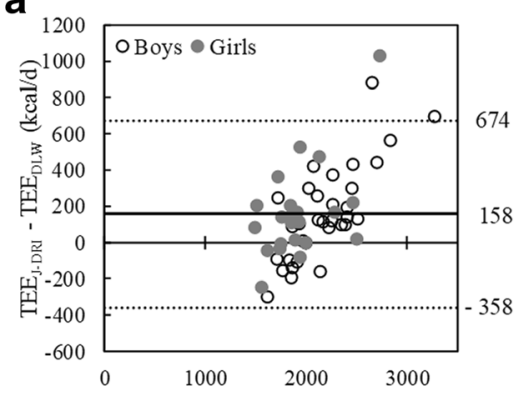

Average of $\mathrm{TEE}_{\mathrm{DLW}}$ and $\mathrm{TEE}_{\mathrm{DRI}}(\mathrm{kcal} / \mathrm{d})$

b

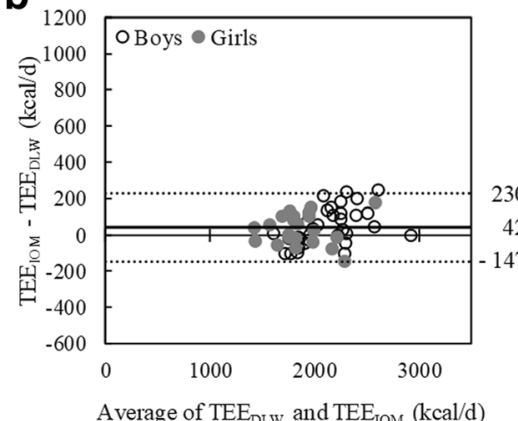

C

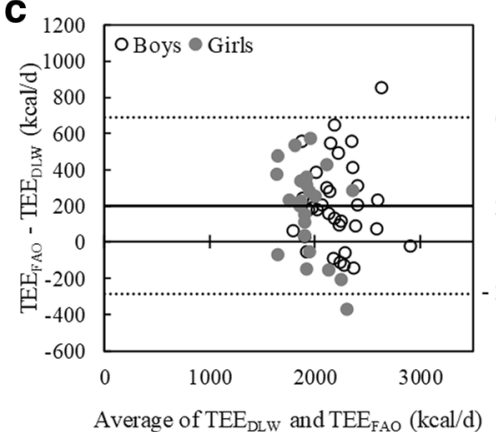

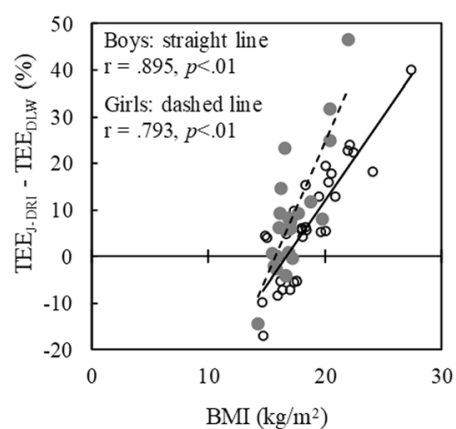
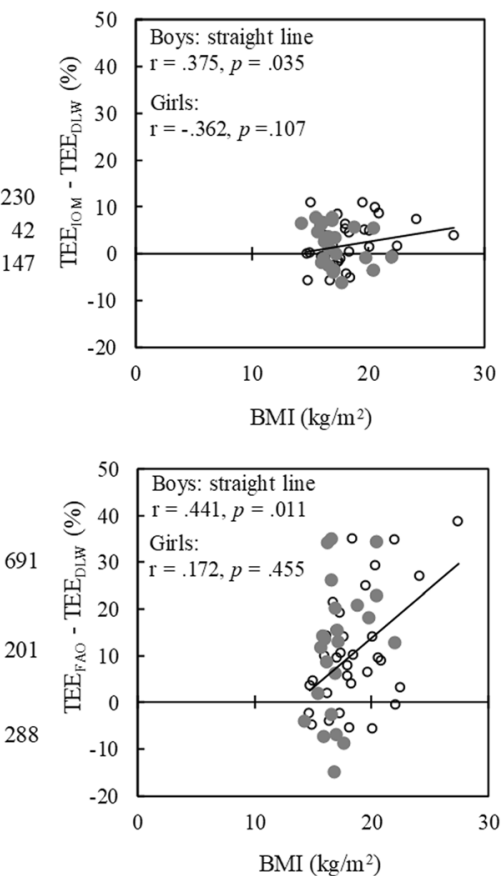

Fig. 1 Bland-Altman plots and relationship between bias of total energy expenditure (TEE) and BMI. In the graph on the left, the thick straight line represents mean, and the dashed lines represent the lower and upper limits of agreement ( \pm 2 standard deviations). a TEE estimated using the equation of Dietary Reference Intakes (DRI) for Japanese [4]. b TEE estimated using the Institute of Medicine (IOM) equation [5]. c TEE estimated using the Food and Agriculture Organization of the United Nation (FAO) equation [12]. In the graph on the right, the relationship between bias (predicted minus measured TEE) and BMI was examined using partial correlation analysis, adjusting for measurement timing

Table 5 Multiple linear regression analysis for predicting total energy expenditure ( $\mathrm{kcal} / \mathrm{d})$ in 10- to 12-year-old children

\begin{tabular}{|c|c|c|c|c|c|c|c|c|c|}
\hline \multirow[b]{2}{*}{$\begin{array}{l}\text { Predictor } \\
\text { variables }\end{array}$} & \multicolumn{3}{|c|}{$\begin{array}{l}\text { Boys and girls } \\
(n=52)\end{array}$} & \multicolumn{3}{|c|}{ Boys $(n=31)$} & \multicolumn{3}{|c|}{ Girls $(n=21)$} \\
\hline & $B$ & $\beta$ & $p$ & $B$ & $\beta$ & $p$ & B & $\beta$ & $p$ \\
\hline FFM (kg) & 51.1 & 0.74 & 0.000 & 47.1 & 0.73 & 0.000 & 55.5 & 0.83 & 0.000 \\
\hline Steps & 0.0505 & 0.51 & 0.000 & 0.0568 & 0.61 & 0.000 & 0.0315 & 0.28 & 0.049 \\
\hline \multirow[t]{2}{*}{ Constant } & -177 & - & 0.000 & -122 & - & 0.664 & -117 & - & 0.729 \\
\hline & \multicolumn{3}{|c|}{$\begin{array}{l}\text { Adjusted } \\
\mathrm{R}^{2}=0.712\end{array}$} & \multicolumn{3}{|c|}{$\begin{array}{l}\text { Adjusted } \\
\mathrm{R}^{2}=0.679\end{array}$} & \multicolumn{3}{|c|}{$\begin{array}{l}\text { Adjusted } \\
\mathrm{R}^{2}=0.654\end{array}$} \\
\hline
\end{tabular}

FFM fat-free mass, $B$ partial regression coefficient, $\beta$ standardised partial regression coefficient

All predictor variables were entered into the regression equation simultaneously of BMI, but even after obtaining PAL from DLW measurements, the Japan-DRI equation overestimates approximately $30 \%$ of children because the BMR standard it employs is a multiple of the weight determined to fit the reference weight and has no intercept [4]. Therefore, as reported in a study of Japanese adults [35], individuals who deviate from the reference weight have greater error, with increasing TEE overestimation in the overweight and underestimation in the underweight.

While the FAO formula [12] similarly overestimates TEE of Japanese children by about $10 \%$, it is advantageous in that it does not require PAL estimation.

The IOM estimation formula [5] of TEE for children aged 9 to 18 years is based on data measured with the DLW method in 525 American subjects in the 5th to 
85th BMI percentile. Bandini et al. [36] reported that bias $\left(\mathrm{TEE}_{\mathrm{IOM}}-\mathrm{TEE}_{\mathrm{DLW}}\right)$ was $-5.8 \pm 7.9 \%$ and accurate estimation was $70 \%$ in 161 girls aged 8 to 12 years, when using DLW-derived PAL for calculation. The accuracy of this estimation method has not been previously evaluated in a Japanese population [4]. In the present study, the average bias between $\mathrm{TEE}_{\mathrm{IOM}}$ and $\mathrm{TEE}_{\mathrm{DLW}}$ was $2.0 \%$, and the rate of accurate estimation exceeded $90 \%$ (Table 4). In addition, the IOM formula estimated TEE with an error within $\pm 10 \%$ and a small influence of subjects' BMI (Fig. 1), suggesting that it is useful for estimating TEE in Japanese 10- to 12-year-old children.

There are several limitations to this study. First, because we did not obtain the participants' birth dates, we assumed ages of 10 years for 5 th grade and 11 years for 6th grade in the REE and IOM equations. In Japan, the 5th grade classes include 10- and 11-year-olds, and 6th grade classes include 11- and 12-year-old children. Assuming that all 5th graders were 11 and all 6th graders were 12 years old, the average REE value would be $-34 \mathrm{kcal} / \mathrm{d}$ $(-2.6 \%$ compared with present data) for boys and $-23 \mathrm{kcal} / \mathrm{d}(-1.9 \%)$ for girls, the average $\mathrm{TEE}_{\mathrm{IOM}}$ value would be $-62 \mathrm{kcal} / \mathrm{d}(-2.9 \%)$ for boys and $-31 \mathrm{kcal} / \mathrm{d}$ $(-1.6 \%)$ for girls, and the average PAL value would be $+0.04(+2.7 \%)$ for boys and $+0.03(+1.9 \%)$ for girls. Second, in TEE estimation by the DLW method, RQ is often substituted with the food quotient obtained from meal records, while the present study applied a factor of 0.85 . However, it has been reported that the estimation error in this case was slight [22]. Third, when estimating PAL, we used estimated REE instead of the measured BMR value. Although the estimation error is considered small [26], the presence of some error must be acknowledged. The current Japan-DRI cited only research that actually measured BMR, while the TEE estimation formula used in the DRI for the United States and Canada included data that estimated BMR [5]. Fourth, the target age was limited to 10 to 12 years. It is unknown whether the results of this study can be applied to other age groups. In the future, data should be collected from children of various ages.

\section{Conclusions}

Our findings suggest that the IOM equation provides a more accurate estimation of TEE in Japanese 10-to 12year-olds than the current Japan-DRI. We further derived a new TEE predictive equation based on FFM and step count per day for this population, the validity of which requires further investigation.

\footnotetext{
Abbreviations

$\%$ fat: Percent fat; ANCOVA: Analysis of covariance; B: Partial regression coefficient; BMR: Basal metabolic rate; BW: Body weight; DLW: Doubly labeled water; DRI: Dietary Reference Intakes; EER: Estimated energy requirements; FAO: Food and Agriculture Organization of the United Nations; FFM: Fat-free mass; FM: Fat mass; kd: ${ }^{2} \mathrm{H}$ elimination rate; ko: ${ }^{18} \mathrm{O}$ elimination rate; $\mathrm{Nd}:{ }^{2} \mathrm{H}$ dilution space; No: ${ }^{18} \mathrm{O}$ dilution space; PA: Physical activity
}

coefficients; PAL: Physical activity level; $\mathrm{rCO}_{2}$ : Carbon dioxide production rates; REE: Resting energy expenditure; RMSE: Root mean squared error; RQ: Respiratory quotient; TBW: Total body water; TEE: Total energy expenditure; TEE $\mathrm{DLw}$ : Total energy expenditure measured by doubly labeled water; TEE $\mathrm{FAO}_{\mathrm{AO}}$ Total energy expenditure predicted by equation of Food and Agriculture Organization of the United Nations; TEEІом: Total energy expenditure predicted by equation of Dietary Reference Intakes for the United States and Canada, Institute of Medicine; TEE J-DRl: Total energy expenditure predicted by equation of Japan Dietary Reference Intakes; $\beta$ : Standardized partial regression coefficient

\section{Acknowledgements}

We thank the participants for their cooperation in this study.

\section{Funding}

This work was supported by Grant-in-Aid for Scientific Research (B) (18300197) and Grant-in-Aid for Scientific Research (B) (20300219).

\section{Availability of data and materials}

The datasets generated and/or analyzed during the current study are available from the corresponding author on reasonable request.

\section{Authors' contributions}

$\mathrm{KI}$ and NE contributed to the conception of this study; $\mathrm{SN}, \mathrm{KH}, \mathrm{NE}, \mathrm{KS}, \mathrm{HO}$, $Y Y$, and MK collected data; SN, YY, and MK analyzed data; $K I$ acquired the research funding and supervised the whole study process; KK performed the statistical analysis and drafted the manuscript. All authors have read and approved the final manuscript.

\section{Ethics approval and consent to participate}

As described in the "Methods", informed consent was obtained from all participants, and the Ethical Committee of Graduate School of Education, Hokkaido University approved the study protocol (Receipt Number: H18-04). All participants and their parents consented to publication of the data.

\section{Consent for publication}

Not applicable.

\section{Competing interests}

The authors declare that they have no competing interests.

\section{Publisher's Note}

Springer Nature remains neutral with regard to jurisdictional claims in published maps and institutional affiliations.

\section{Author details \\ ${ }^{1}$ Graduate School of Health and Sports Science, Doshisha University, Kyoto, Japan. ${ }^{2}$ Department of Early Childhood Education, Kyoto Bunkyo Junior College, Kyoto, Japan. ${ }^{3}$ Department of Nutrition and Metabolism, National Institutes of Biomedical Innovation, Health and Nutrition, Tokyo, Japan. \\ ${ }^{4}$ Faculty of Health and Medical Sciences, Kyoto Gakuen University, Kyoto, Japan. ${ }^{5}$ Faculty of Health and Sports Science, Doshisha University, Kyoto, Japan. ${ }^{6}$ Faculty of Education, Art and Science, Yamagata University, Yamagata, Japan. ${ }^{7}$ School of Management, Shizuoka Sangyo University, Shizuoka, Japan.}

Received: 28 July 2017 Accepted: 3 November 2017 Published online: 15 November 2017

\section{References}

1. Minister of Health, Labour and Welfare, Japan. Overview of Dietary Reference Intakes for Japanese (2015). 2014.http://www.mhlw.go.jp/file/06Seisakujouhou-10900000-Kenkoukyoku/Overview.pdf. Accessed 27 July 2017

2. Tabata I, Ebine N, Kawashima Y, Ishikawa-Takata K, Tanaka S, Higuchi M, et al. Dietary reference intakes for Japanese 2010: energy. J Nutr Sci Vitaminol (Tokyo). 2012;59:S26-35.

3. Okubo H, Sasaki S, Rafamantanantsoa HH, Ishikawa-Takata K, Okazaki H, Tabata I. Validation of self-reported energy intake by a self-administered diet history questionnaire using the doubly labeled water method in 140 Japanese adults. Eur J Clin Nutr. 2008;62:1343-50. 
4. Minister of Health, Labour and Welfare, Japan: Dietary Reference Intakes for Japanese, 2015. 1-1-1. Energy. http://www.mhlw.go.jp/file/05-Shingikai10901000-Kenkoukyoku-Soumuka/0000083871.pdf. Accessed 27 July 2017.

5. Institute of Medicine of the National Academies (US). Dietary reference intakes for energy, carbohydrate, fiber, fat, fatty acids, cholesterol, protein, and amino acids (macronutrients). Washington (D.C.): The National Academies Press; 2002

6. Speakman JR. The history and theory of the doubly labeled water technique. Am J Clin Nutr. 1998;68:932s-8s.

7. Westerterp KR. Doubly labelled water assessment of energy expenditure: principle, practice, and promise. Eur J Appl Physiol. 2017;17:1277-85.

8. Park J, Kazuko IT, Kim E, Kim J, Yoon J. Estimating free-living human energy expenditure: practical aspects of the doubly labeled water method and its applications. Nutr Res Pract. 2014;8:241-8.

9. Adachi M, Sasayama K, Hikihara Y, Okishima K, Mizuuchi H, Sunami Y, et al. Assessing daily physical activity in elementary school students used by accelerometer. Jpn J Phys Fitness Sports Med. 2007;56:347-56.

10. Ishikawa-Takata K, Kaneko K, Koizumi K, Ito C. Comparison of physical activity energy expenditure in Japanese adolescents assessed by EW4800P triaxial accelerometry and the doubly labelled water method. Br J Nutr. 2013;110:1347-55.

11. Tanaka S, Ohkawara K, Ishikawa-Takata K, Morita A, Watanabe S. Accuracy of predictive equations for basal metabolic rate and contribution of abdominal fat distribution to basal metabolic rate in obese Japanese people. AntiAging Med. 2008;5:17-21.

12. World Health Organization, Food and Agriculture Organization of the United Nations, United Nations University. Human energy requirements: Report of a Joint FAO/WHO/UNU Expert Consultation, food and nutrition technical report series 1. Rome: Food and Agriculture Organization of the United Nations; 2004.

13. Cunningham JJ. Body composition as a determinant of energy expenditure: a synthetic review and a proposed general prediction equation. Am J Clin Nutr. 1991;54:963-9.

14. Itoi A, Yamada Y, Watanabe Y, Kimura M. Physical activity, energy intake, and obesity prevalence among urban and rural schoolchildren aged 11-12 years in Japan. Appl Physiol Nutr Metab. 2012;37:1189-99.

15. Park J, Ishikawa-Takata K, Tanaka S, Mekata Y, Tabata I. Effects of walking speed and step frequency on estimation of physical activity using accelerometers. J Physiol Anthropol. 2011;30:119-27.

16. De Craemer M, De Decker E, Santos-Lozano A, Verloigne M, De Bourdeaudhuij I, Deforche B, et al. Validity of the Omron pedometer and the actigraph step count function in preschoolers. J Sci Med Sport. 2015;18: 289-93.

17. Namba H, Yamaguchi $Y$, Yamada $Y$, Tokushima S, Hatamoto $Y$, Sagayama $H$, et al. Validation of web-based physical activity measurement systems using doubly labeled water. J Med Internet Res. 2012;14:e123.

18. Sagayama H, Hamaguchi G, Toguchi M, Ichikawa M, Yamada Y, Ebine $N$, et al. Energy requirement assessment in Japanese table tennis players using the doubly labeled water method. Int J Sport Nutr Exerc Metab. 2017;27(5):421-28.

19. Racette SB, Schoeller DA, Luke AH, Shay K, Hnilicka J, Kushner RF. Relative dilution spaces of $2 \mathrm{H}$ - and 180-labeled water in humans. Am J Phys. 1994; 267:E585-90.

20. Sagayama H, Yamada Y, Racine NM, Shriver TC, Schoeller DA. Dilution space ratio of $2 \mathrm{H}$ and 180 of doubly labeled water method in humans. J Appl Physiol. 2016;120:1349-54.

21. Schoeller DA, Ravussin E, Schutz Y, Acheson KJ, Baertschi P, Jequier E. Energy expenditure by doubly labeled water: validation in humans and proposed calculation. Am J Phys. 1986;250:R823-30.

22. Black AE, Prentice AM, Coward WA. Use of food quotients to predict respiratory quotients for the doubly-labelled water method of measuring energy expenditure. Hum Nutr Clin Nutr. 1986;40:381-91.

23. Weir JB. New methods for calculating metabolic rate with special reference to protein metabolism. J Physiol. 1949;109:1-9.

24. International Atomic Energy Agency. IAEA HUMAN HEALTH SERIES no. 3 Vienna: Vienna International Centre; 2009. p. 37-40.

25. International Atomic Energy Agency. IAEA HUMAN HEALTH SERIES no. 12. Vienna, Austria: Vienna International Centre; 2010. p. 9-11.

26. Kaneko K, Ito C, Koizumi K, Watanabe S, Umeda Y, Ishikawa-Takata K. Resting energy expenditure (REE) in six- to seventeen-year-old Japanese children and adolescents. J Nutr Sci Vitaminol (Tokyo). 2013;59:299-309.
27. Sun M, Gower BA, Nagy TR, Trowbridge CA, Dezenberg C, Goran MI. Total, resting, and activity-related energy expenditures are similar in Caucasian and African-American children. Am J Phys. 1998;274:E232-7.

28. Tanaka C, Reilly JJ, Tanaka M, Tanaka S. Seasonal changes in objectively measured sedentary behavior and physical activity in Japanese primary school children. BMC Public Health. 2016;16:969.

29. Cole TJ, Bellizzi MC, Flegal KM, Dietz WH. Establishing a standard definition for child overweight and obesity worldwide: international survey. BMJ. 2000; 320:1240-3.

30. DeLany JP, Bray GA, Harsha DW, Volaufova J. Energy expenditure in preadolescent African American and white boys and girls: the baton rouge Children's study. Am J Clin Nutr. 2002;75:705-13.

31. Westerterp KR. Control of energy expenditure in humans. Eur J Clin Nutr. 2017;71:340-4.

32. Ohkawara K, Ishikawa-Takata K, Park JH, Tabata I, Tanaka S. How much locomotive activity is needed for an active physical activity level: analysis of total step counts. BMC Res Notes. 2011;4:512.

33. Park JH, Ishikawa-Takata K, Lee SJ, Kim EK, Lim KW, Kim HR, et al. Association between daily step counts and physical activity level among Korean elementary schoolchildren. J Exerc Nutr Biochem. 2016;20:51-5.

34. Tanaka C, Tanaka M, Okuda M, Inoue S, Aoyama T, Tanaka S. Association between objectively evaluated physical activity and sedentary behavior and screen time in primary school children. BMC Res Notes. 2017;10:175.

35. Miyake R, Tanaka S, Ohkawara K, Ishikawa-Takata K, Hikihara Y, Taguri E, et al. Validity of predictive equations for basal metabolic rate in Japanese adults. J Nutr Sci Vitaminol (Tokyo). 2011;57:224-32.

36. Bandini LG, Lividini K, Phillips SM, Must A. Accuracy of dietary reference intakes for determining energy requirements in girls. Am J Clin Nutr. 2013; 98:700-4.

\section{Submit your next manuscript to BioMed Central and we will help you at every step:}

- We accept pre-submission inquiries

- Our selector tool helps you to find the most relevant journal

- We provide round the clock customer support

- Convenient online submission

- Thorough peer review

- Inclusion in PubMed and all major indexing services

- Maximum visibility for your research

Submit your manuscript at www.biomedcentral.com/submit
) Biomed Central 